Article

\title{
Expression of Antioxidant Enzymes in Patients with Uterine Polyp, Myoma, Hyperplasia, and Adenocarcinoma
}

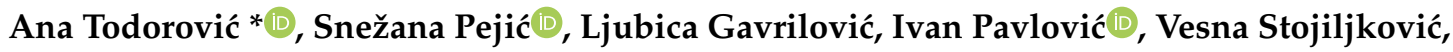 \\ Nataša Popović and Snežana B. Pajović $\mathbb{D}$ \\ Laboratory of Molecular Biology and Endocrinology, "Vinča" Institute of Nuclear Sciences, \\ University of Belgrade, P.O. Box 522, 11001 Belgrade, Serbia; snezana@vin.bg.ac.rs (S.P.); \\ gljubica@vin.bg.ac.rs (L.G.); pavlovic@vin.bg.ac.rs (I.P.); vesnas@vin.bg.ac.rs (V.S.); \\ natasap@vin.bg.ac.rs (N.P.); pajovic@vin.bg.ac.rs (S.B.P.) \\ * Correspondence: anato@vin.bg.ac.rs; Tel.: +381-116-455-561
}

Received: 1 April 2019; Accepted: 4 April 2019; Published: 11 April 2019

\begin{abstract}
We previously found that compared to patients with benign uterine diseases (polyps, myomas), patients with premalignant (hyperplasia simplex and complex) and malignant (adenocarcinoma) lesions had enhanced lipid peroxidation and altered uterine antioxidant enzyme (AOE) activities. To further elucidate the mechanism of the observed changes, we examined protein and mRNA levels of copper-zinc superoxide dismutase (CuZnSOD), catalase (CAT), glutathione peroxidase (GPx), glutathione reductase (GR), and transcription factor Nrf2. We also examined correlations of AOE expression with AOE activity, lipid hydroperoxides (LOOH) level, and level of Nrf2. Our results showed decreased CuZnSOD, CAT, and Nrf2 levels, and increased GPx and GR levels in hyperplasias, while in patients with adenocarcinoma, the level of CAT was decreased and GR was increased, compared to benign groups. Similar changes in mRNA levels were also detected, indicating predominantly translational control of the AOE expression. The positive correlation of enzyme expression/activity was recorded for CuZnSOD, GPx, and GR, but only among groups with benign diseases. Only GR and GPx expressions were positively correlated with LOOH. Nrf2 protein was positively correlated with mRNA levels of CuZnSOD and GR. Observed results indicate involvement of diverse redox mechanisms in etiopathogenesis of different gynecological diseases, and may improve redox-based approaches in current clinical practice.
\end{abstract}

Keywords: antioxidant enzymes; polyps; myoma; hyperplasia; adenocarcinoma

\section{Introduction}

During the life cycle, aerobic organisms are exposed to a number of endogenous and exogenous sources of reactive oxygen species (ROS). To achieve redox homeostasis they developed a powerful antioxidant system (AOS) [1], whose main enzyme components are superoxide dismutase (SOD), catalase (CAT), glutathione peroxidase (GPx), and glutathione reductase (GR). The transcription factor Nrf2 is responsible for regulating a battery of antioxidant and detoxification enzymes [2,3], as well as processes such as stress response, proliferation, and proteasomal degradation $[4,5]$. Nrf2 was also identified as an important transcription factor regulating development, progression, and chemoresistance of cancer [6].

Cancer develops over three stages, initiation, promotion, and progression, and oxidative stress is associated with each of them [7]. Endometrial cancer ranks as the fourth most common neoplasm in women from European countries [8]. It has been shown that premalignant changes precede the malignant transformation of the uterus, which is why hyperplasia may be considered as a precursor of 
endometrial cancer [9-11]. Despite numerous studies, the molecular processes involved in multi-stage development of endometrial cancer are still not completely known.

We have previously shown that gonadotropins influence the antioxidant enzyme (AOE) activity in women with uterine hyperplasia simplex, hyperplasia complex, leiomyoma, and polyps [12-15]. Also, the extent of AOE and lipid hydroperoxides ( $\mathrm{LOOH})$ alterations varied with the examined gynecological diagnosis, including adenocarcinoma [16]. The aim of this study was to further clarify the mechanism responsible for the observed $\mathrm{AO}$ alterations. Therefore, we examined the changes of protein and mRNA levels of copper-zinc superoxide dismutase (CuZnSOD), catalase (CAT), glutathione peroxidase (GPx), glutathione reductase (GR), and Nrf2 in uterine tissue of patients with benign (polyps and myomas), premalignant (hyperplasia simplex and hyperplasia complex), and malignant (adenocarcinoma) transformations. We also examined correlations of AOE expression with the AOE activity, lipid hydroperoxides (LOOH) level, and level of Nrf2. Results showed significant differences in AO parameters among examined groups of gynecological patients, and indicated their important role in pathophysiological processes in endometrium.

\section{Materials and Methods}

\subsection{Subjects}

A total of 79 subjects from the Department of Gynecology and Obstetrics admitted for routine checkups or for abnormal uterine bleeding were included in this prospective study. According to diagnosis and histological results, subjects were divided into five groups: polypus endometrii (PE, $n=16$, median age $43 \pm 2 \mathrm{yr}$, range 31-57 yr), uterus myomatosus (UM, $n=12$, median age $46 \pm 2 \mathrm{yr}$, range 34-54 yr), hyperplasia simplex endometrii $(\mathrm{SH}, n=25$, median age $49 \pm 3 \mathrm{yr}$, range 32-60 yr), hyperplasia complex endometrii $(\mathrm{CH}, n=21$, median age $47 \pm 3 \mathrm{yr}$, range $45-59 \mathrm{yr})$, and adenocarcinoma endometrii, stage I (ACE, $n=5$, median age $58 \pm 4 \mathrm{yr}$, range $49-61 \mathrm{yr}$ ). Patients' characteristics are summarized in Table 1 . The research was approved by the Ethics Committee of the Clinical Center (No. 27/06-2006), and in accordance with the World Medical Association Declaration of Helsinki. Samples were taken after provision of informed consent. The patients received no medical treatment in the 6 months before sampling.

Table 1. Patients characteristics.

\begin{tabular}{cccccc}
\hline Age (years) & 25-34 (7) & 35-44 (22) & 45-54 (41) & 55-64 (6) & $\mathbf{6 5 \pm 7 9 ( 3 )}$ \\
\hline Parity (N) & $0(3)$ & $1(6)$ & $2(29)$ & $3(24)$ & $>3(17)$ \\
Abortions (N) & $0(1)$ & $1(30)$ & $2(16)$ & $3(16)$ & $>3(16)$ \\
Uterine bleeding $^{1}(\mathrm{~N})$ & None (26) & MP (19) & MR (15) & MPM (19) & \\
Diagnosis $^{2}(\mathrm{~N})$ & PE (16) & UM (12) & SH (25) & CH (21) & ACE (5) \\
\hline
\end{tabular}

1 MP—Metrorrhagia prolongata, MR-Metrorrhagia recidivans, MPM-Metrorrhagia postmenopausi. ${ }^{2}$ $\mathrm{PE}$ - polypus endometrii, $\mathrm{UM}$ - uterus myomatosus, $\mathrm{SH}$-hyperplasia simplex endometrii, $\mathrm{CH}$-hyperplasia complex endometrii, ACE—adenocarcinoma endometrii.

\subsection{Samples and Methods}

Tissue samples were removed and homogenized on ice in a phosphate buffer of $\mathrm{pH} 7.8(1: 2 \mathrm{~g} / \mathrm{mL})$. Enzyme assays and concentration of $\mathrm{LOOH}$ were measured according to the procedures described previously [13]. Protein concentration in prepared samples was measured by Lowry et al.'s method [17], and used to express enzyme activities of CuZnSOD, CAT, GPx, and GR as Units (U) or mU per milligram of protein ( $\mathrm{U}$ or $\mathrm{mU} / \mathrm{mg}$ protein). Level of $\mathrm{LOOH}$ was also expressed relative to protein

Western blot was performed as previously described [18]. Immuno-blot was conducted using antibodies against CuZnSOD (Stressgen, 1:7500), GPx1 (Santa Cruz 1:500), GR (Santa Cruz, 1:500), actin (Abcam, 1:500), Nrf2 (Santa Cruz, 1:500), and horseradish peroxidase (HRP) conjugated secondary antibodies. Immunoreactive proteins were visualized using enhanced chemiluminescence (ECL) detection. Densitometry of protein bands, normalized to $\beta$-actin, was performed by Image J software. 
Quantitative RT-PCR analysis: Total RNA was isolated from endometrial tissue using Trizol reagent (Invitrogen, USA) according to the manufacturer's protocol. RNA purity was evaluated by determining the 260/280 ratio (GeneQuant Pro, Biochrom, UK), and $1 \mu \mathrm{g}$ of total RNA was used for cDNA synthesis with a High Capacity RNA-to-cDNA Master Mix (Applied Biosistems, USA), as described in the manufacturer's specifications. TaqManPCR assays were performed using Assay-on-Demand Gene Expression Products (Applied Biosystems, USA) for CuZnSOD (Hs00172187_m1), CAT (Hs00156308_m1), GPx (Hs02516751_s1), GR (Hs00167317_m1), Nrf2 (Hs00232352_m1), and POLR2A (Hs00172187_m1). RT-qPCR assay was performed with ABI Prism 7000 Sequence Detection System (Applied Biosystems, Foster City, CA, USA) under the following conditions: $50{ }^{\circ} \mathrm{C}(2 \mathrm{~min}), 95{ }^{\circ} \mathrm{C}(10 \mathrm{~min})$, followed by 40 cycles of $95{ }^{\circ} \mathrm{C}(15 \mathrm{~s}), 60{ }^{\circ} \mathrm{C}(1 \mathrm{~min})$. All experiments were performed in triplicate, and the data were normalized to POLR2A.

\subsection{Statistical Analysis}

Statistical analysis was performed using the Kruskal-Wallis method followed by Dunn's multiple-comparison test. Spearman's rank correlation coefficient was used to investigate associations between enzyme protein levels and activities, as well as between enzyme protein levels and lipid peroxidation. A 2-tailed $\mathrm{p}<0.05$ was considered statistically significant. All data were analyzed using GraphPad Prism software (version 4.0, GraphPad Software, Inc., San Diego, CA, USA).

\section{Results}

Endometrial protein level of CuZnSOD in patients with myoma was comparable to that observed in patients with polyps and adenocarcinoma, whereas in patients with simple or complex hyperplasia it was significantly lower $(\mathrm{p}=0.035, \mathrm{p}=0.046$, respectively; Figure $1 \mathrm{~A})$.

A
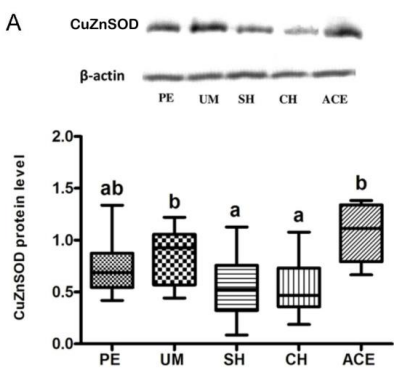

C
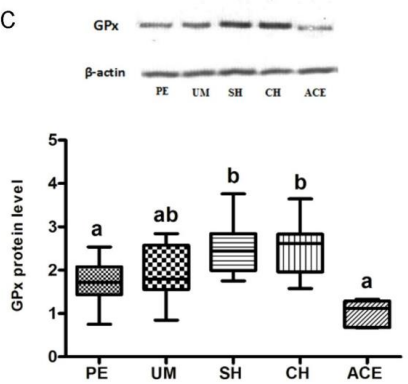

$B$
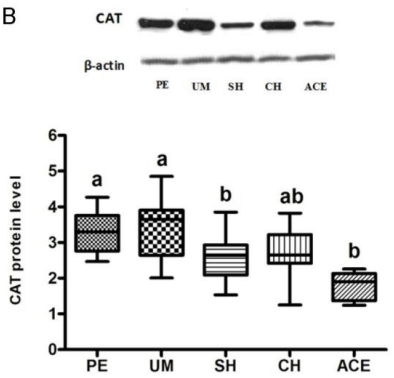

D
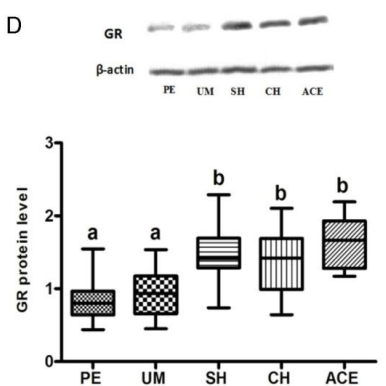

Figure 1. Representative Western blot bands and quantitative analysis of CuZnSOD (A), CAT (B), GPx (C), and GR (D) in endometrium of patients diagnosed with polypus endometrii (PE), uterus myomatosus (UM), simple hyperplasia (SH), complex hyperplasia $(\mathrm{CH})$, and adenocarcinoma endometrii (ACE). Mean protein levels $( \pm S D$ ) are represented by the box; medians are plotted inside a box; the whiskers extend to the 5th and 95th percentiles. Values with the same letter $(a, b)$ did not differ significantly from each other $(p>0.05)$.

There was no significant difference in CAT level between the patients with polyps and myoma, or compared to those with hyperplasia complex. In comparison with polyps and myoma, the protein 
level of CAT was decreased in subjects with hyperplasia simplex $(p=0.005, p=0.045$, respectively; Figure 1B) and adenocarcinoma ( $p=0.001, p=0.002$, respectively; Figure 1B).

Patients with polyps and myoma had a comparable GPx level to that observed in patients with adenocarcinoma. Compared to women with polyps and adenocarcinoma, the GPx level was significantly higher in patients with hyperplasia simplex $(p=0.001, p<0.001$, respectively) and hyperplasia complex ( $p=0.001, p<0.001$, respectively; Figure 1C).

Compared to patients with polyps and myoma, significant elevation of GR level was recorded in groups with hyperplasia simplex $(p<0.001, p=0.005$, respectively), hyperplasia complex $(p=0.001$, $p=0.049$, respectively), and adenocarcinoma ( $p=0.007, p=0.050$, respectively) (Figure 1D).

Correlation analysis of AOE activity against their protein levels for benign and premalignant/malignant groups of patients is shown in Figure 2. The positive correlation was observed in benign group for CuZnSOD $(r=0.43, p=0.019$; Figure 2A1), GPx $(r=0.49, p=0.006$; Figure 2C1), and GR $(r=0.39, p=0.033$; Figure 2D1). There was no activity/level correlation in premalignant/malignant group, except for CuZnSOD where negative activity/level correlation was recorded $(r=-0.37, p=0.005 ;$ Figure 2A2).
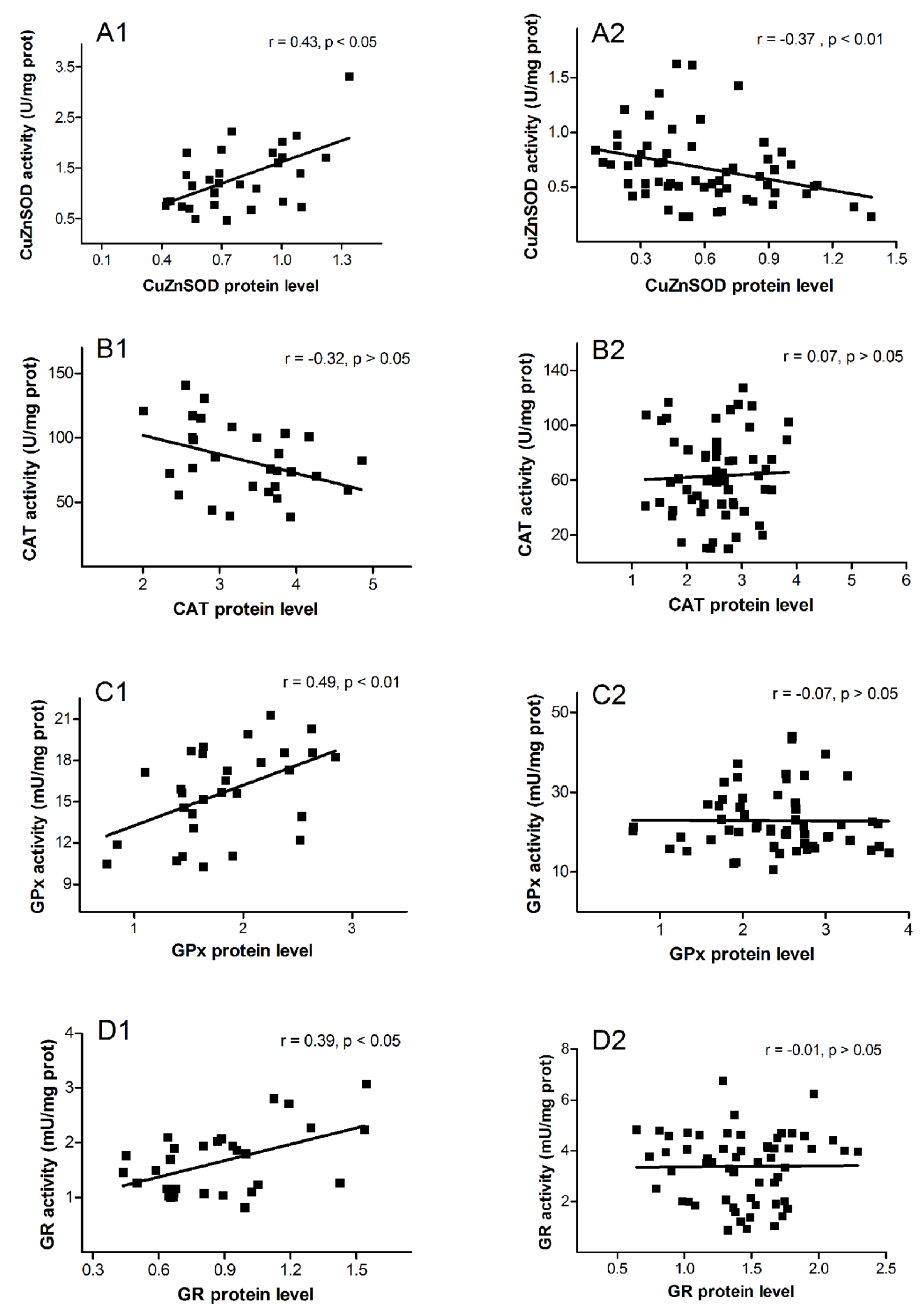

Figure 2. Scatter plots of the activity against quantity of CuZnSOD: (A1) benign and (A2) premalignant and malignant groups. CAT: (B1) benign and (B2) premalignant and malignant groups. GPx: (C1) benign and (C2) premalignant and malignant groups. GR: (D1) benign and (D2) premalignant and malignant groups. Benign group was composed of polyps and myomas groups. Premalignant/malignant group consisted of hyperplasia simplex, hyperplasia complex, and adenocarcinoma. Enzyme activities were expressed as Units (U) or mU per milligram of total cell protein ( $\mathrm{U}$ or $\mathrm{mU} / \mathrm{mg}$ protein). Protein levels were normalized to $\beta$-actin. 
LOOH level was negatively correlated to protein level of CAT ( $r=-0.50, p<0.001$; Figure 3B), and positively correlated with levels of GPx $(r=0.24, p=0.026$; Figure $3 C)$ and GR $(r=0.41, p<0.001$; Figure 3D), whereas no correlation was found with the level of CuZnSOD.
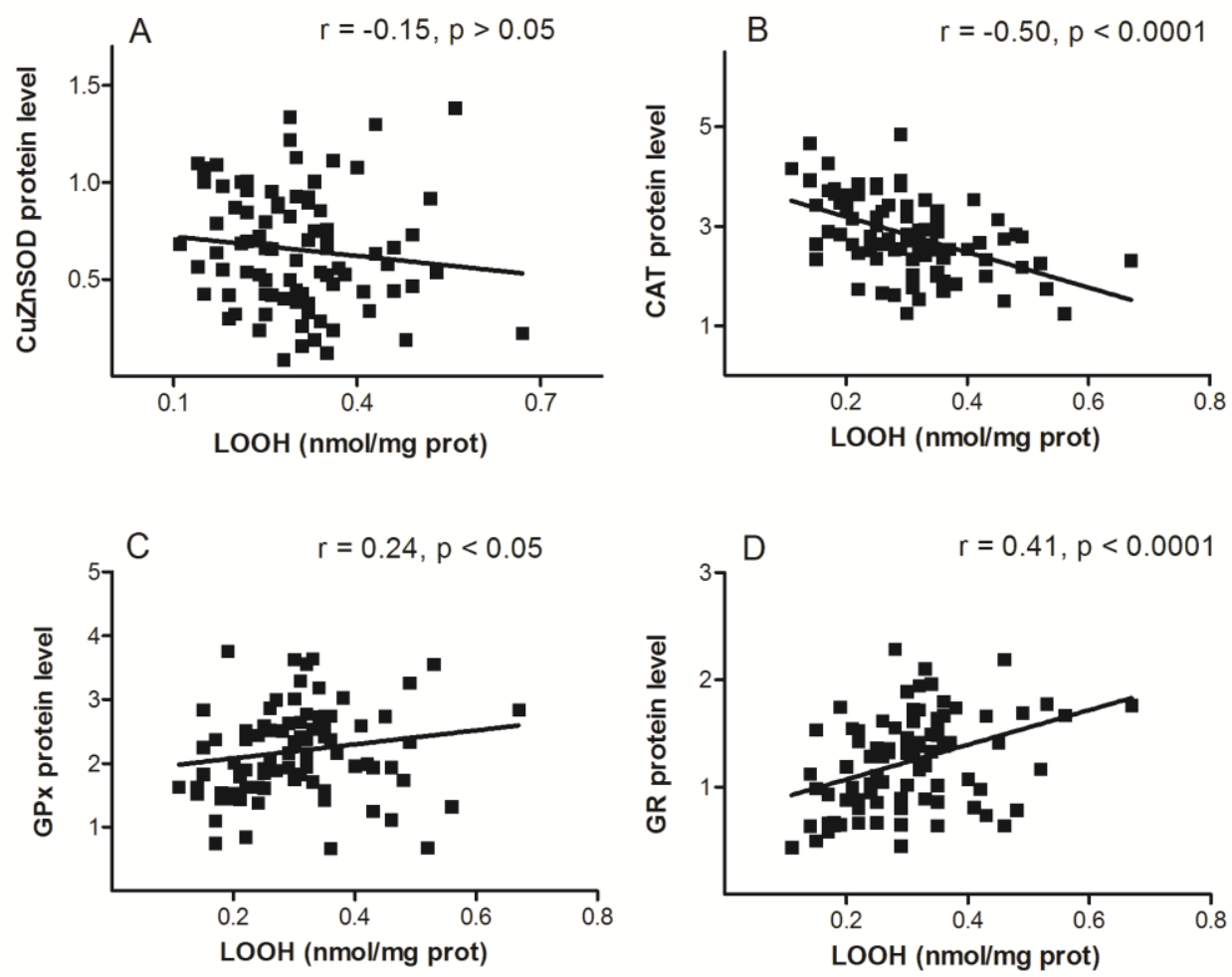

Figure 3. Scatter plots of lipid hydroperoxides-LOOH level against proteins levels of copper-zinc superoxide dismutase-CuZnSOD (A), catalase-CAT (B), glutathione peroxidase-GPx (C), and glutathione reductase-GR (D). Protein levels were normalized to $\beta$-actin.

Data on Figure 4A indicated that compared to the groups with polyps and myoma, CuZnSOD mRNA level was lowered in group with $\mathrm{SH}$ and it was not significantly changed in adenocarcinoma group. In patients with hyperplasias and adenocarcinoma, the CAT mRNA level showed a tendency to decrease, while the GPx and GR mRNAs inclined toward increase, compared to PE and UM groups (Figure 4B-D).

Compared to the groups with polyps and myoma, Nrf2 mRNA level was lowered in the groups with hyperplasias and adenocarcinoma (Figure 5A). Data on Figure 5B showed that Nrf2 protein level was significantly decreased in patients with hyperplasia $(\mathrm{SH}$ and $\mathrm{CH})$, related to the groups with polyps, myoma, and adenocarcinoma.

Nrf2 protein level was positively correlated to mRNA levels of CuZnSOD and GR, negatively correlated to mRNA level of GPx, and not correlated to the mRNA level of CAT. 

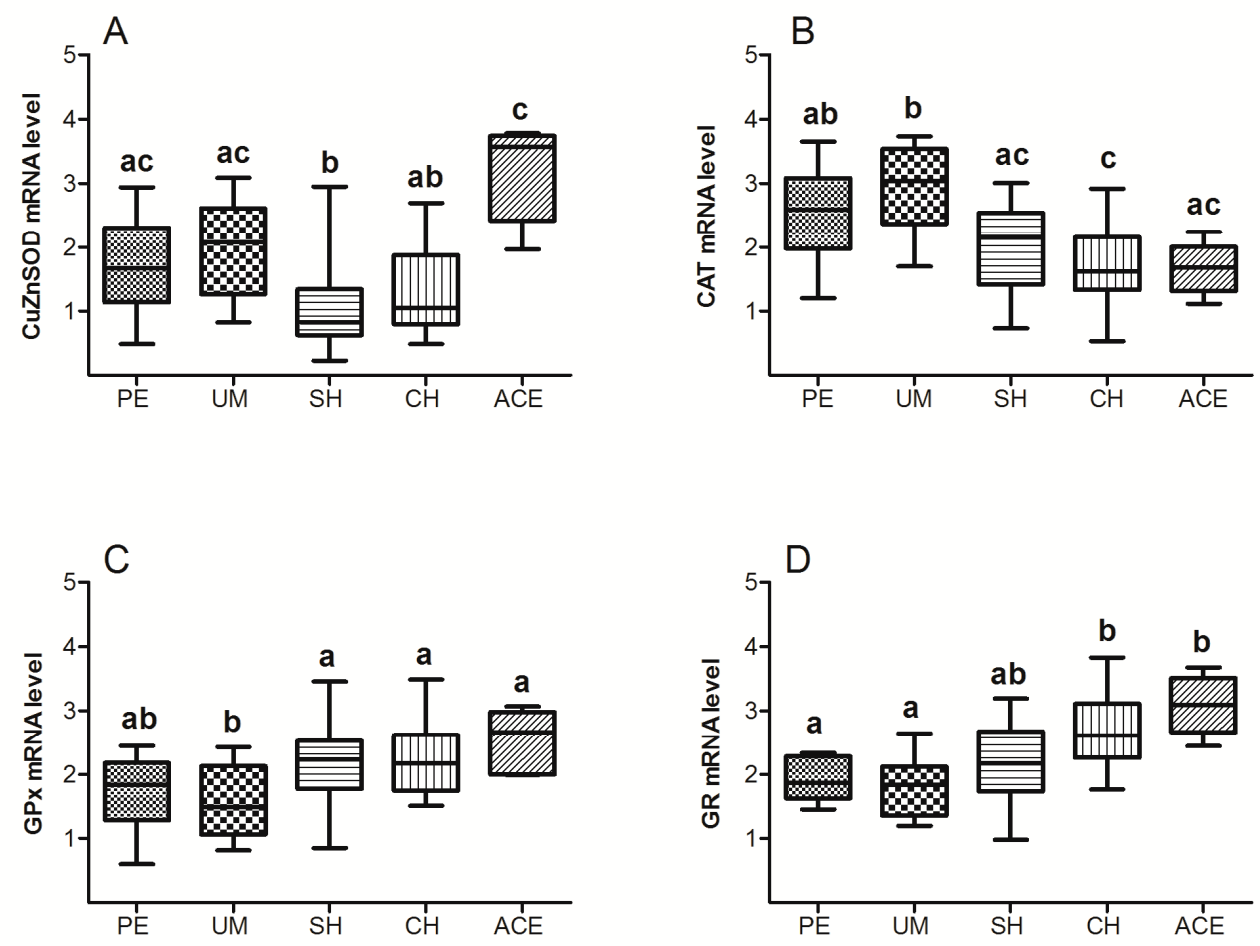

Figure 4. Box plots represent relative gene expression for CuZnSOD (A), CAT (B), GPx (C), and GR (D) in endometrium of patients diagnosed with polypus endometrii (PE), uterus myomatosus (UM), simple hyperplasia $(\mathrm{SH})$, complex hyperplasia $(\mathrm{CH})$, and adenocarcinoma endometrii (ACE). Data were determined by qRT PCR and normalized to endogenous POLR2A expression. Mean mRNA levels $( \pm \mathrm{SD})$ are represented by the box; medians are plotted inside a box; the whiskers extend to the 5th and 95th percentiles. Values with the same letter $(a, b)$ did not differ significantly from each other $(p>0.05)$.

A

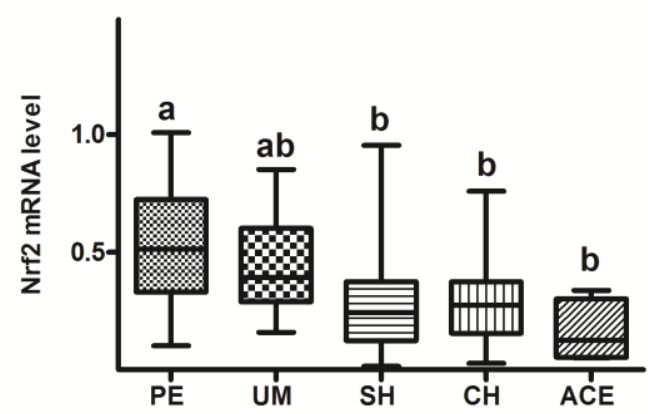

B

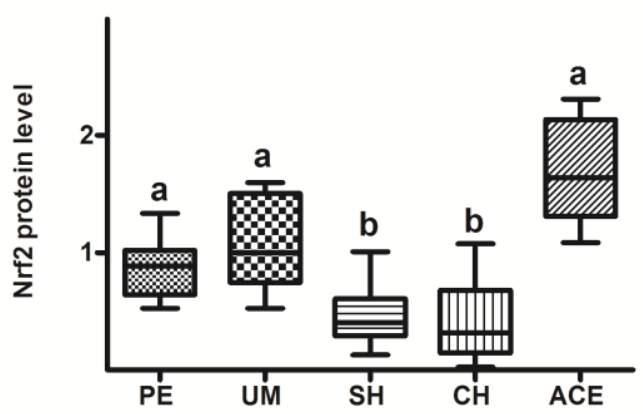

Figure 5. Box plots represent relative levels of Nrf2 mRNA (A) and Nrf2 protein (B) in endometrium of patients diagnosed with polypus endometrii (PE), uterus myomatosus (UM), simple hyperplasia (SH), complex hyperplasia $(\mathrm{CH})$, and adenocarcinoma endometrii (ACE). Mean mRNA and protein levels $( \pm S D)$ are represented by the box; medians are plotted inside a box; the whiskers extend to the 5th and 95th percentiles. Values with the same letter $(a, b)$ did not differ significantly from each other $(p>0.05)$.

\section{Discussion}

In this study, we recorded a different expression of AOE in transformed endometrial tissue. Furthermore, we noticed that positive correlation of AOE expression/activity observed in patients with benign endometrial changes was mostly lost in premalignant and malignant groups, pointing to different molecular mechanisms that regulate AOE levels in examined gynecological diseases. 
In patients with hyperplasia simplex and hyperplasia complex, the CuZnSOD expression was decreased compared to myoma group (Figure 1A), suggesting that reduced CuZnSOD levels favor the formation of premalignant lesions. Reduced levels of CuZnSOD were also found during the malignant transformation of lung [19], prostatic [20], and renal cells [21]. According to findings of Oberley and Oberley [22] on papillomas and squamous cell carcinoma, the SOD and CAT reduction leads to a pro-oxidant state of cells, facilitating tumorigenesis. Similarly, Bostwick et al. [23] and Srivastava et al. [24] observed that SOD level decreased during the progression of cervical and prostate cancer. Our results indicate that in adenocarcinoma tissue, the $\mathrm{CuZnSOD}$ protein level was increased compared to hyperplasia groups (Figure 1A), although the same increase was not observed previously regarding CuZnSOD activity [11]. This may suggest that ROS present in tumor cells stimulate the expression of CuZnSOD protein, but simultaneously partly reduce CuZnSOD activity, as already noted in colorectal cancer tissue [25].

Regulation of $\mathrm{CuZnSOD}$ expression seems to be performed at the transcriptional level, since the trend of changes in CuZnSOD mRNA (Figure 4A) was followed by those of CuZnSOD protein. Such regulation can be provided by several transcriptional factors [26], most probably by redox-dependent regulators, such as Egr1 (Early Growth Response-1), AP1 (Activating Protein 1), NF-кB (Nuclear Factor-KappaB), and Nrf2 [27]. Altered level of $\mathrm{O}_{2}{ }^{-}$can further affect downstream cell signaling targets and eventually affect cell sensitivity, proliferation, and even death. It has been shown that in hepatic stellate cells, superoxide anion can induce apoptosis through the mechanism that involves reducing cellular glutathione level and activating Jun N-terminal kinase (JNK) and p38 [28], or by inducing death receptor CD95 (Fas) on the cell surface [29]. Also, research on the M14 melanoma cells indicated that intracellular $\mathrm{O}_{2}{ }^{-}$regulates tumor cell sensitivity through the caspase activation pathway [30], while others showed that $\mathrm{O}_{2}{ }^{-}$might function as a mitogenic stimuli by inducing the expression of early growth-related genes, such as c-fos and c-jun [31].

Observed changes in CuZnSOD level during the course of malignant transformation may have clinical significance due to the influence that cell redox status has on tumor progression. The study of Skrzycki et al. [25] suggested that changes in protein level and activity of SOD isoenzymes might be an adaptive response to the oxidative stress. As SOD isoenzymes are one of the main redox state controllers, therapies affecting SOD activity or expression at different stages of cancer could aid in elimination of transformed cells.

Regarding CuZnSOD activity/expression relations, our results showed that CuZnSOD activity was positively correlated with its expression in patients with benign gynecological disorders (Figure 2A1), while in patients with hyperplasia and adenocarcinoma, a negative correlation was observed (Figure 2A2). This indicates that during the transition from benign to premalignant and malignant endometrial conditions, regulation of $\mathrm{CuZnSOD}$ activity also transits from expressional to dominantly post-translational level.

Changes in CAT level during carcinogenesis, the mechanism of these changes, and their significance for course of the disease are still incompletely understood. The CAT activity and expression in a large number of tumors are found to be reduced in comparison to normal cells [32,33]. Our results are consistent with these findings, pointing to the decreased CAT level in both premalignant and malignant endometrial tissue (Figure 1B). Since increased level of $\mathrm{H}_{2} \mathrm{O}_{2}$ is associated with DNA damage, genetic instability [34,35], cell proliferation [36], and the regulation of apoptosis [37], a significant reduction of CAT recorded in endometrial hyperplasia may have an important role in cellular transition from premalignant to malignant state.

Presumed mechanisms through which $\mathrm{H}_{2} \mathrm{O}_{2}$ affects the downstream paths of cellular signaling include modulation of interleukins [38], epidermal growth factor (EGF) [39], and tumor necrosis factor- $\alpha(\mathrm{TNF}-\alpha)[40]$, as well as inactivation of enzymes, such as protein tyrosine phosphatases (PTPs) [41], peroxidase [42], and catalase [43]. Beside playing an important physiological role in the stimulation of cell proliferation [44,45], $\mathrm{H}_{2} \mathrm{O}_{2}$ may also induce apoptosis associated with increased expression of p53, Puma, Noxa, and Bax in several cell types, including colon cancer and human 
cervical carcinoma HeLa cells [46,47]. It can also act as a promoter of neoplastic transformation through modulation of the PI3K/AKT signaling pathway due to oxidation of the PTP1B [48,49] and PTEN [50].

Although the exact mechanism of CAT regulation during the development of malignancy remains unknown, the absence of a positive correlation between its activity and level in all examined patients (Figure 2B1,B2) suggested that CAT activity in endometrial tissue is governed by a mechanism other than expression. Moreover, the results of our study indicated that this regulation is performed at the level of mRNA, whose amount (similar to protein level) was decreased in hyperplasia and adenocarcinoma groups (Figure 4B).

It was shown that GPx plays an important role in cancer development, and that a loss of heterozygosity $(\mathrm{LOH})$ at the GPx1 locus and changes in GPx expression may be the early events in cancerogenesis [51]. Epigenetic GPx alterations may also affect the process of malignant transformation. Previous studies showed that changes in GPx level could disrupt the balance between ROS production and AO defense, and thereby influence cancer development [52-54]. Our results also indicated that significant changes in GPx levels occurred during premalignant and malignant endometrial transformation. Specifically, the GPx protein level in patients with hyperplasia showed a tendency to increase compared to patients with polyps and myoma (Figure 1C). Similar alterations were observed at the level of mRNA (Figure 4C), indicating transcriptional regulation of this enzyme. Observed changes in GPx expression can affect the cell proliferation in several ways. It has been shown that GPx may inhibit apoptosis by removing hydroperoxides [55], or by alternating Bax/Bcl-2 ratio [56], which may occur as a relatively early event in tumor development [57].

In adenocarcinoma, the GPx protein level was not significantly changed compared to groups with benign uterine changes. However, a significant drop in Gpx protein level was recorded in the adenocarcinoma group compared to hyperplasias, although it was not accompanied by changes in its mRNA (Figures $1 \mathrm{C}$ and $4 \mathrm{C}$ ). A possible reason for this disproportion might be the increased proteasomal degradation, which occurs in conditions of mild oxidative stress, and the fact that protein sensitivity to proteolysis increases after exposure to oxidants. Similarly, expression of GPx was not increased in some other cancer types [58,59]. Considering the already increased $\mathrm{H}_{2} \mathrm{O}_{2}$ production in cancer cells [60], it may be concluded that simultaneous reduction of CAT and GPx in adenocarcinoma could additionally raise $\mathrm{H}_{2} \mathrm{O}_{2}$ level, and thus affect further progression and metastasis of cancer [57].

The positive correlation between GPx activity/level was detected in group of patients with polyps and myoma, but not in those with hyperplasia and adenocarcinoma (Figure $2 \mathrm{C} 1, \mathrm{C} 2$ ). This is in agreement with the findings that glutathione redox cycle is a major source of protection against low levels of oxidative stress (expected in benign endometrial changes), whereas CAT becomes more significant in protecting against severe oxidative stress (characteristic for premalignant and malignant cells) [61].

GR is considered as a central enzyme of cellular antioxidant defense, as it catalyzes the reduction of oxidized glutathione disulfide (GSSG) to the sulfhydryl form, glutathione (GSH). The GSH level is essential for preserving normal cell functions, preventing malignant transformation, and for resistance of already-transformed, malignant cells. Results of this study showed that compared to patients with polyps and myoma, levels of GR protein and GR mRNA were elevated in women with both types of hyperplasia and adenocarcinoma (Figures 1D and 4D). The noticed increase might be significant for uterine carcinogenesis, as it is known that many types of malignant tumors are characterized by the increased expression of enzymes involved in the GSH metabolism [53]. Indirectly, the results of our study also pointed out the possible therapy resistance of uterine adenocarcinoma, as the high level of GSH was previously recorded in some radio- or chemo-resistant cancers, such as breast tumor, melanoma, and lung cancer [62-64]. Our previous data showed that GR activity also rises during premalignant and malignant processes in the human endometrium [11]. However, a positive association of the GR level and activity was observed only in patients with benign uterine changes (Figure 2D1). In groups with hyperplasias and adenocarcinoma, the tested GR activity was not 
correlated with GR protein level (Figure 2D2), and therefore was presumably not regulated solely by its expression.

In general, according to our results presented in Figure 2 (A2, B2, C2, and D2), expression of AOE enzymes in hyperplastic and malignantly0transformed uterine tissue was not correlated with AOE activity, so increases in AOE protein levels do not necessarily lead to increases in their enzyme activities. Observed discordance could be the consequence of the oxidative stress, which although induces AOE expression by modulating different transcription factors [65], can also oxidatively alter the enzymes, thereby reducing or completely suppressing their activity [66,67]. As an outcome, oxidative stress presumed in premalignant and malignant tissue can cause accumulation of damaged, non-degradable proteins, without increasing their activity.

The $\mathrm{LOOH}$ is a well-known marker of oxidative stress $[15,68]$ and peroxidative damage of membrane lipids. A part of our research concerning the relation of $\mathrm{LOOH}$ and AOE expression showed that only GPx and GR were positively correlated with $\mathrm{LOOH}$ level (Figure 3). This was not surprising, given that glutathione-associated metabolism is a major defense mechanism, not only against ROS, but also against their toxic products. Coordinated regulation of glutathione-dependent enzymes is also a common phenomenon and is achieved, at least in part, through the antioxidant responsive element (ARE), located in the promoters of many genes that are inducible by oxidative and chemical stress [69].

The results of our study have shown that in both groups with hyperplasia, the Nrf2 protein level was decreased in comparison to patients with benign and adenocarcinoma diagnoses (Figure 5B). Reduced Nrf2 level in the endometrium of patients with hyperplasia simplex and hyperplasia complex could be the cause of reduced detoxification and antioxidant capacities of these cells. Such a prooxidative environment certainly favors the formation of structural and functional cell damage, and formation of initial, premalignant lesion. Regarding the increase in Nrf2 level observed in the adenocarcinoma group, a similar increase has already been shown in the study of Chen et al. [70] in malignant tissue related to their precursor lesions. The authors have measured the Nrf2 expression in benign endometrium, endometrial cancers, as well as in their precursor lesions, and concluded that Nrf2 overexpression was closely associated with endometrial neoplasms with serous differentiation. Their study showed that alteration of Nrf2 expression may represent one of the early molecular events in endometrial carcinogenesis and that overexpression of Nrf2 may be used as a diagnostic marker in surgical pathology. Some other studies on human cancers have also shown that increase in the expression of Nrf2 can enhance the Nrf2-dependent mechanisms of protection, thereby intensifying the growth of cancer cells and providing them with chemoresistance to a large number of chemotherapeutic drugs [71,72].

Discrepancy between mRNA changes and the amount of its protein in adenocarcinoma tissue (Figure 5A,B) indicates the presence of an additional, posttranscriptional regulation of the Nrf2 level. The most likely mechanism is the interference in the correct binding of Keap1 to Nrf2, which prevents ubiquitination and proteasomal decomposition of Nrf2 molecules, a process that maintains Nrf2 at the physiological level. Possible causes of such a constitutive stabilization of Nrf2 molecules could be the mutations in the Nrf2 or Keap1 genes, already identified in many types of cancer $[73,74]$, or the accumulation of proteins that interfere with Keap1-Nrf2 interactions, such as p62 and p21 [75,76]. However, the most likely cause is the methylation in the promoter region of Keap1 gene, as the connection between oxidative stress and hypermethylation of genes that can induce cancerogenesis was already shown in different cell types [77].

Results of our study showed positive correlation between the level of Nrf2 protein and mRNA levels of CuZnSOD and GR (Figure 6A,D). The highest level of Nrf2 observed in adenocarcinoma tissue is probably a key event in the induction of CuZnSOD and GR expression, since in that tissue the highest protein and mRNA levels for CuZnSOD and GR were also recorded. Contrary to those results, the protein level of Nrf2 was negatively correlated with GPx mRNA (Figure 6C), and it was not correlated with level of CAT mRNA (Figure 6B). It seems that some other mechanism or transcriptional factor dominates the Nrf2 transcriptional regulation of these two AOE. The induction 
effect of Nrf2 in these cases could be suppressed by competence, as it was experimentally shown on the mouse hepatocarcinoma cell line. In these cells, p53 binds to promoters containing ARE elements, and thus directly blocks the binding of Nrf2 and the transcriptional induction of several AOE genes [78]. Negative regulation of Nrf2 signaling was also described for some other molecules, such as NF-kappaB/p65 [79] and c-Myc [80].
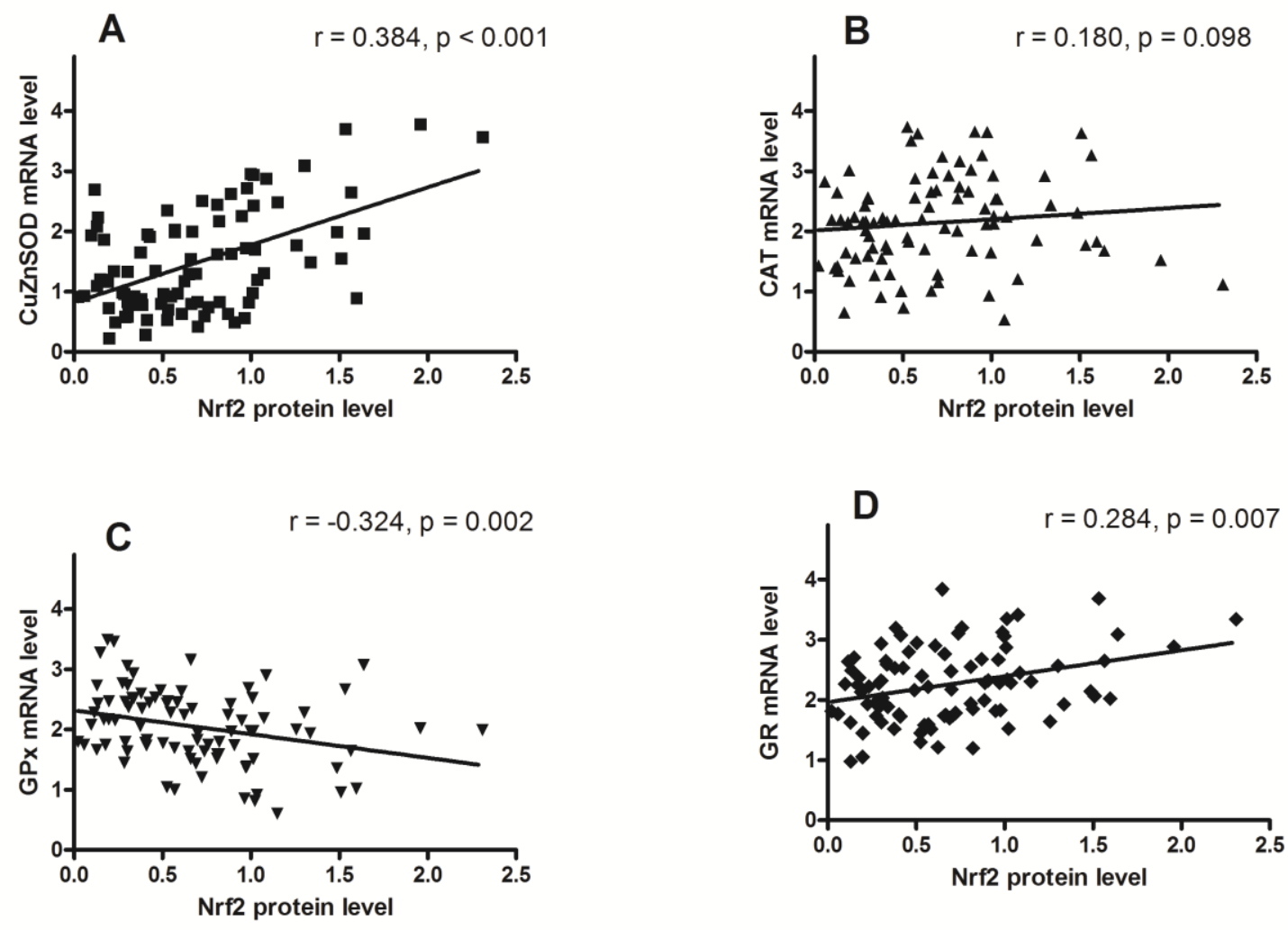

Figure 6. Scatter plots of Nrf2 protein level against mRNA levels of CuZnSOD (A), CAT (B), GPx (C), and GR (D). Protein levels were normalized to $\beta$-actin, and mRNA was normalized to POLR2A.

To the best of our knowledge, this is the first study to investigate the expression of the four most important $\mathrm{AOE}$ enzymes and their regulation by the Nrf2 in various gynecological diseases. However, several limitations of our study should be noted. In addition to the relatively small number of samples, their distribution in groups was uneven. Also, due to unethical uterine sampling of healthy women, groups with hyperplasias and adenocarcinoma were compared with groups with benign changes, which can lead to false positive or false negative results in relation to healthy controls. Future studies should replicate the results with a larger sample set, and perhaps in an in vitro model system comparing benign and malignantly transformed cells with healthy ones.

\section{Conclusions}

The results of our study clearly showed that in the course of benign, premalignant, and malignant uterine transformation significant changes occurred in expression level of $\mathrm{Nrf} 2$, and consequently on transcriptional and translational levels of AOE. It is also evident that the impact of AOE expression on their enzyme activity depends not only on the type of the enzyme, but also on the type of endometrial transformation. Observed findings could contribute to a better insight into molecular mechanisms connecting oxidative stress with different gynecological disorders, and to a better understanding of therapeutic approaches based on altering the cellular redox status. 
Author Contributions: Conceptualization, A.T. and S.P. Data curation, I.P. Formal analysis, A.T., S.P., and L.G. Investigation, A.T. Methodology, L.G. and V.S. Supervision, S.B.P. Validation, N.P. Writing-original draft, A.T. Writing-review and editing, S.P. and S.B.P.

Funding: This work was supported by the Ministry of Education, Science, and Technological Development of the Republic of Serbia (Grant numbers 41027, 173041).

Conflicts of Interest: The authors declare no conflict of interest.

\section{References}

1. Halliwell, B.; Gutteridge, J.M.C. Free Radicals in Biology and Medicine, 4th ed.; Oxford University Press: Oxford, UK, 2007.

2. Zhu, H.; Itoh, K.; Yamamoto, M.; Zweier, J.L.; Li, Y. Role of Nrf2 signaling in regulation of antioxidants and phase 2 enzymes in cardiac fibroblasts: Protection against reactive oxygen and nitrogen species-induced cell injury. FEBS Lett. 2005, 579, 3029-3036. [CrossRef]

3. Akino, N.; Wada-Hiraike, O.; Terao, H.; Honjoh, H.; Isono, W.; Fu, H.; Hirano, M.; Miyamoto, Y.; Tanikawa, M.; Harada, M.; et al. Activation of Nrf2 might reduce oxidative stress in human granulosa cells. Mol. Cell. Endocrinol. 2018, 470, 96-104. [CrossRef]

4. Kwak, M.-K.; Wakabayashi, N.; Greenlaw, J.L.; Yamamoto, M.; Kensler, T.W. Antioxidants Enhance Mammalian Proteasome Expression through the Keap1-Nrf2 Signaling Pathway. Mol. Cell. Boil. 2003, 23, 8786-8794. [CrossRef]

5. Malhotra, D.; Portales-Casamar, E.; Singh, A.; Srivastava, S.; Arenillas, D.; Happel, C.; Shyr, C.; Wakabayashi, N.; Kensler, T.W.; Wasserman, W.W.; et al. Global mapping of binding sites for Nrf2 identifies novel targets in cell survival response through ChIP-Seq profiling and network analysis. Acids Res. 2010, 38, 5718-5734. [CrossRef] [PubMed]

6. Basak, P.; Sadhukhan, P.; Sarkar, P.; Sil, P.C. Perspectives of the Nrf-2 signaling pathway in cancer progression and therapy. Toxicol. Rep. 2017, 4, 306-318. [CrossRef]

7. Klaunig, J.E.; Kamendulis, L.M.; Hocevar, B.A. Oxidative stress and oxidative damage in carcinogenesis. Toxicol. Pathol. 2010, 38, 96-109. [CrossRef]

8. Bray, F.; Loos, A.H.; Oostindier, M.; Weiderpass, E. Geographic and temporal variations in cancer of the corpus uteri: Incidence and mortality in pre- and postmenopausal women in Europe. Int. J. 2005, 117, 123-131. [CrossRef]

9. Mazur, M.T. Endometrial hyperplasia/adenocarcinoma. A conventional approach. Ann. Diagn. Pathol. 2005, 9, 174-181. [PubMed]

10. Gültekin, M.; Dogan, N.U.; Aksan, G.; Ozgul, N. Management of endometrial hyperplasia. Minerva Ginecol. 2010, 62, 433-445.

11. Kwak, M.-K.; Kensler, T.W. Induction of $26 \mathrm{~S}$ proteasome subunit PSMB5 by the bifunctional inducer 3-methylcholanthrene through the Nrf2-ARE, but not the AhR/Arnt-XRE, pathway. Biochem. Biophys. Res. Commun. 2006, 345, 1350-1357. [CrossRef]

12. Pejic, S.; Todorovic, A.; Stojiljkovic, V.; Pavlovic, I.; Gavrilovic, L.; Popovic, N.; Pajovic, S.B. Antioxidant status and sex hormones in women with complex endometrial hyperplasia. Cell. Mol. Biol. 2016, 62, 51-56.

13. Pejić, S.; Todorović, A.; Stojiljković, V.; Pavlovic, I.; Gavrilović, L.; Popovic, N.; Pajovic, S.B. Antioxidant Status and Sex Hormones in Women with Simple Endometrial Hyperplasia. In Basic Principles and Clinical Significance of Oxidative Stress; IntechOpen: London, UK, 2015; Chapter 9; pp. 243-279.

14. Pejić, S.; Todorović, A.; Stojiliković, V.; Gavrilović, L.; Popović, N.; Pajović, S.B. Antioxidant status in women with uterine leiomyoma: relation with sex hormones. An. Acad. Bras. Ciênc. 2015, 87, 1771-1782. [CrossRef]

15. Pejić, S.A.; Kasapović, J.D.; Todorović, A.U.; Stojiljković, V.R.; Gavrilović, L.V.; Popović, N.M.; Pajović, S.B. Antioxidant enzymes in women with endometrial polyps: relation with sex hormones. Eur. J. Obstet. Gynecol. 2013, 170, 241-246. [CrossRef]

16. Pejić, S.; Todorović, A.; Stojiljković, V.; Kasapović, J.; Pajović, S.B. Antioxidant enzymes and lipid peroxidation in endometrium of patients with polyps, myoma, hyperplasia and adenocarcinoma. Reprod. Boil. Endocrinol. 2009, 7, 149. [CrossRef]

17. Lowry, O.H.; Rosebrough, N.J.; Farr, A.L.; Randall, R.J. Protein measurement with the Folin phenol reagent. J. Boil. Chem. 1951, 193, 265-275. 
18. Pejić, S.; Todorović, A.; Stojiljković, V.; Cvetković, D.; Lučić, N.; Radojičić, R.M.; Saičić, Z.S.; Pajovic, S.B. Superoxide dismutase and lipid hydroperoxides in blood and endometrial tissue of patients with benign, hyperplastic and malignant endometrium. An. Acad. Bras. Ciênc. 2008, 80, 515-522. [CrossRef]

19. Güner, G.A.; Islekel, H.; Oto, Ö.; Hazan, E.; Acikel, U. Evaluation of some antioxidant enzymes in lung carcinoma tissue. Cancer Letters 1996, 103, 233-239. [CrossRef]

20. Baker, A.M.; Oberley, L.W.; Cohen, M.B. Expression of antioxidant enzymes in human prostatic adenocarcinoma. Prostate 1997, 32, 229-233. [CrossRef]

21. Oberley, T.D.; Sempf, J.M.; Oberley, L.W. Immunogold analysis of antioxidant enzymes in common renal cancers. Histol. Histopathol. 1996, 11, 153-160.

22. Oberley, T.D.; Oberley, L.W. Oxygen radicals and cancer. In Free Radicals in Aging; Yu, B.P., Ed.; CRC Press: Boca Raton, FL, USA, 1993; pp. 247-267.

23. Bostwick, D.G.; Alexander, E.E.; Singh, R.; Shan, A.; Qian, J.; Santella, R.M.; Oberley, L.W.; Yan, T.; Zhong, W.; Jiang, X.; et al. Antioxidant enzyme expression and reactive oxygen species damage in prostatic intraepithelial neoplasia and cancer. Cancer 2000, 89, 123-134. [CrossRef]

24. Srivastava, A.; Srivastava, S.; Natu, S.; Gupta, A.; Pal, K.; Agarwal, G.; Singh, U.; Goel, M. Lipid peroxidation and antioxidants in different stages of cervical cancer: Prognostic significance. Indian J Cancer 2009, 46, 297. [CrossRef]

25. Skrzycki, M.; Majewska, M.; Podsiad, M.; Czeczot, H. Expression and activity of superoxide dismutase isoenzymes in colorectal cancer. Biochim. Pol. 2009, 56, 663-670. [CrossRef]

26. Miao, L.; Clair, D.K.S. Regulation of Superoxide Dismutase Genes: Implications in Diseases. Free. Radic. Boil. Med. 2009, 47, 344-356. [CrossRef]

27. Milani, P.; Gagliardi, S.; Cova, E.; Cereda, C. SOD1 Transcriptional and Posttranscriptional Regulation and Its Potential Implications in ALS. Neurol. Res. Int. 2011, 2011, 458427. [CrossRef]

28. Dunning, S.; Hannivoort, R.A.; De Boer, J.F.; Faber, K.N.; Moshage, H.; Buist-Homan, M.; Buist-Homan, M. Superoxide anions and hydrogen peroxide inhibit proliferation of activated rat stellate cells and induce different modes of cell death. Liver Int. 2009, 29, 922-932. [CrossRef]

29. Clément, M.V.; Stamenkovic, I. Superoxide anion is a natural inhibitor of FAS-mediated cell death. EMBO J. 1996, 15, 216-225. [CrossRef]

30. Pervaiz, S.; Ramalingam, J.K.; Hirpara, J.L.; Clement, M.-V. Superoxide anion inhibits drug-induced tumor cell death. FEBS Lett. 1999, 459, 343-348. [CrossRef]

31. Roy, H.B. Superoxide and hydrogen peroxide in relation to mammalian cell proliferation. Free Radic. Biol. Med. 1995, 18, 775-794.

32. Sato, K.; Ito, K.; Kohara, H.; Yamaguchi, Y.; Adachi, K.; Endo, H. Negative regulation of catalase gene expression in hepatoma cells. Mol. Cell. Boil. 1992, 12, 2525-2533. [CrossRef]

33. Min, J.Y.; Lim, S.-O.; Jung, G. Downregulation of catalase by reactive oxygen species via hypermethylation of CPG island II on the catalase promoter. FEBS Lett. 2010, 584, 2427-2432. [CrossRef]

34. Benhusein, G.M.; Mutch, E.; Aburawi, S.; Williams, F.M. Genotoxic effect induced by hydrogen peroxide in human hepatoma cells using comet assay. J. Med. 2010, 5, 1-6. [CrossRef]

35. Gopalakrishnan, K.; Low, G.K.M.; Ting, A.P.L.; Srikanth, P.; Slijepcevic, P.; Hande, M.P.; Low, G.K.; Ting, A.P. Hydrogen peroxide induced genomic instability in nucleotide excision repair-deficient lymphoblastoid cells. Genome Integr. 2010, 1, 16. [CrossRef]

36. Li, M.; Zhao, L.; Liu, J.; Liu, A.-L.; Zeng, W.-S.; Luo, S.-Q.; Bai, X.-C.; Zeng, W.; Luo, S.; Bai, X. Hydrogen Peroxide Induces G2Cell Cycle Arrest and Inhibits Cell Proliferation in Osteoblasts. Anat. Rec. 2009, 292, 1107-1113. [CrossRef]

37. Del Bello, B.; Paolicchi, A.; Comporti, M.; Pompella, A.; Maellaro, E. Hydrogen peroxide produced during $\gamma$-glutamyl transpeptidase activity is involved in prevention of apoptosis and maintenance of proliferation in U937 cells. FASEB J. 1999, 13, 69-79. [CrossRef]

38. Sattler, M.; Winkler, T.; Verma, S.; Byrne, C.H.; Shrikhande, G.; Salgia, R.; Griffin, J.D. Hematopoietic growth factors signal through the formation of reactive oxygen species. Blood 1999, 93, 2928-2935.

39. Kang, S.W. Epidermal Growth Factor (EGF)-induced Generation of Hydrogen Peroxide. ROLE IN EGF RECEPTOR-MEDIATED TYROSINE PHOSPHORYLATION. J. Boil. Chem. 1997, 272, 217-221. 
40. Krieger-Brauer, H.I.; Kather, H. The stimulus-sensitive H2O2-generating system present in human fat-cell plasma membranes is multireceptor-linked and under antagonistic control by hormones and cytokines. Biochem. J. 1995, 307, 543-548. [CrossRef]

41. Meng, T.-C.; Fukada, T.; Tonks, N.K. Reversible oxidation and inactivation of protein tyrosine phosphatases in vivo. F1000-Post-publication peer review of the biomedical literature 2002, 9, 387-399. [CrossRef]

42. Arnao, M.; Acosta, M.; Del Rio, J.; Garcia-Canovas, F. Inactivation of peroxidase by hydrogen peroxide and its protection by a reductant agent. Biochim. et Biophys. (BBA) Struct. Mol. Enzym. 1990, 1038, 85-89. [CrossRef]

43. Ghadermarzi, M.; Moosavi-Movahedi, A.A. Determination of the Kinetic Parameters for the "Suicide Substrate" Inactivation of Bovine Liver Catalase by Hydrogen Peroxide. J. Enzym. Inhib. 1996, 10, 167-175. [CrossRef]

44. Finkel, T. Oxygen radicals and signaling. Curr. Opin. Cell. Biol. 1998, 10, 248-253. [CrossRef]

45. Sundaresan, M.; Yu, Z.X.; Ferrans, V.J.; Irani, K.; Finkel, T. Requirement for generation of $\mathrm{H} 2 \mathrm{O} 2$ for platelet-derived growth factor signal transduction. Science 1995, 270, 296-299. [CrossRef]

46. Pallepati, P.; Averill-Bates, D. Mild thermotolerance induced at 40 degrees c increases antioxidants and protects hela cells against mitochondrial apoptosis induced by hydrogen peroxide: Role of p53. Arch. Biochem. Biophys. 2010, 495, 97-111. [CrossRef]

47. Yu, J.; Zhang, L. PUMA, a potent killer with or without p53. Oncogene 2008, 27, S71-S83. [CrossRef]

48. Salmeen, A.; Andersen, J.N.; Myers, M.P.; Meng, T.-C.; Hinks, J.A.; Tonks, N.K.; Barford, D. Redox regulation of protein tyrosine phosphatase 1B involves a sulphenyl-amide intermediate. Nature 2003, 423, 769-773. [CrossRef]

49. Lee, S.-R.; Kwon, K.-S.; Kim, S.-R.; Rhee, S.G. Reversible Inactivation of Protein-tyrosine Phosphatase 1B in A431 Cells Stimulated with Epidermal Growth Factor. J. Boil. Chem. 1998, 273, 15366-15372. [CrossRef]

50. Kwon, J.; Lee, S.-R.; Yang, K.-S.; Ahn, Y.; Kim, Y.J.; Stadtman, E.R.; Rhee, S.G. Reversible oxidation and inactivation of the tumor suppressor PTEN in cells stimulated with peptide growth factors. Proc. Natl. Acad. Sci. USA 2004, 101, 16419-16424. [CrossRef]

51. Hu, Y.J.; Dolan, M.E.; Bae, R.; Yee, H.; Roy, M.; Glickman, R.; Kiremidjian-Schumacher, L.; Diamond, A.M. Allelic Loss at the GPx-1 Locus in Cancer of the Head and Neck. Boil. Element Res. 2004, 101, 097-106. [CrossRef]

52. Skrzydlewska, E.; Sulkowski, S.; Koda, M.; Zalewski, B.; Kanczuga-Koda, L.; Sulkowska, M. Lipid peroxidation and antioxidant status in colorectal cancer. World J. Gastroenterol. 2005, 11, 403-406. [CrossRef]

53. Skrzydlewska, E.; Stankiewicz, A.; Sulkowska, M.; Sulkowski, S.; Kasacka, I. Antioxidant Status and Lipid Peroxidation in Colorectal Cancer. J. Toxicol. Environ. Heal. A 2001, 64, 213-222. [CrossRef]

54. Beevi, S.S.; Rasheed, M.H.; Geetha, A. Evidence of oxidative and nitrosative stress in patients with cervical squamous cell carcinoma. Clin. Chim. 2007, 375, 119-123. [CrossRef]

55. Skrzycki, M.; Czeczot, H. Superoxide dismutase as a potential therapeutic agent. Adv. Clin. Exp. Med. 2007, 16, 561-568.

56. Faucher, K.; Rabinovitch-Chable, H.; Cook-Moreau, J.; Barrière, G.; Sturtz, F.; Rigaud, M. Overexpression of human GPX1 modifies Bax to Bcl-2 apoptotic ratio in human endothelial cells. Mol. Cell. Biochem. 2005, 277, 81-87. [CrossRef]

57. Pergola, P.E.; Raskin, P.; Toto, R.D.; Meyer, C.J.; Huff, J.W.; Grossman, E.B.; Krauth, M.; Ruiz, S.; Audhya, P.; Christ-Schmidt, H.; et al. Bardoxolone Methyl and Kidney Function in CKD with Type 2 Diabetes. New Engl. J. Med. 2011, 365, 327-336. [CrossRef]

58. Murawaki, Y.; Tsuchiya, H.; Kanbe, T.; Harada, K.; Yashima, K.; Nozaka, K.; Tanida, O.; Kohno, M.; Mukoyama, T.; Nishimuki, E.; et al. Aberrant expression of selenoproteins in the progression of colorectal cancer. Cancer Letters 2008, 259, 218-230. [CrossRef]

59. Rebsch, C.M.; Penna, F.J.; Copeland, P.R.; Iii, F.J.P. Selenoprotein expression is regulated at multiple levels in prostate cells. Cell Res. 2006, 16, 940-948. [CrossRef]

60. López-Lázaro, M. Dual role of hydrogen peroxide in cancer: Possible relevance to cancer chemoprevention and therapy. Cancer Letters 2007, 252, 1-8. [CrossRef]

61. Cao, C.; Leng, Y.; Liu, X.; Yi, Y.; Li, P.; Kufe, D. Catalase Is Regulated by Ubiquitination and Proteosomal Degradation. Role of the c-Abl and Arg Tyrosine Kinases. Biochemistry 2003, 42, 10348-10353. [CrossRef] 
62. Perry, R.R.; Mazetta, J.; Levin, M.; Barranco, S.C. Glutathione levels and variability in breast tumors and normal tissue. Cancer 1993, 72, 783-787. [CrossRef]

63. Carretero, J.; Obrador, E.; Anasagasti, M.J.; Martin, J.J.; Vidal-Vanaclocha, F.; Estrela, J.M. Growth-associated changes in glutathione content correlate with liver metastatic activity of B16 melanoma cells. Clin. Exp. Metastasis 1999, 17, 567-574. [CrossRef]

64. Honda, T.; Coppola, S.; Ghibelli, L.; Cho, S.H.; Kagawa, S.; Spurgers, K.B.; Brisbay, S.M.; A Roth, J.; E Meyn, R.; Fang, B.; et al. GSH depletion enhances adenoviral bax-induced apoptosis in lung cancer cells. Gene Ther. 2004, 11, 249-255. [CrossRef]

65. Sen, C.K.; Packer, L. Antioxidant and redox regulation of gene transcription. FASEB J. 1996, 10, 709-720. [CrossRef]

66. Cho, C.-S.; Lee, S.; Lee, G.T.; Woo, H.A.; Choi, E.-J.; Rhee, S.G. Irreversible Inactivation of Glutathione Peroxidase 1 and Reversible Inactivation of Peroxiredoxin II by H2O2 in Red Blood Cells. Antioxidants Redox Signal. 2010, 12, 1235-1246. [CrossRef]

67. Kim, S.Y.; Kwon, O.J.; Park, J.-W. Inactivation of catalase and superoxide dismutase by singlet oxygen derived from photoactivated dye. Biochimie 2001, 83, 437-444. [CrossRef]

68. Pajovic, S.; Saičić, Z.; Pejić, S.; Kasapović, J.; Stojiljković, V.; Kanazir, D. Antioxidative biomarkers and cancerogenesis. Jugosl. Med. biohemija 2006, 25, 397-402. [CrossRef]

69. Lecker, S.H.; Goldberg, A.L.; Mitch, W.E. Protein Degradation by the Ubiquitin-Proteasome Pathway in Normal and Disease States. J. Am. Soc. Nephrol. 2006, 17, 1807-1819. [CrossRef]

70. Chen, N.; Yi, X.; Abushahin, N.; Pang, S.; Zhang, D.; Kong, B.; Zheng, W. Nrf2 expression in endometrial serous carcinomas and its precancers. Int. J. Clin. Exp. Pathol. 2010, 4, 85-96.

71. Cho, J.-M.; Manandhar, S.; Lee, H.-R.; Park, H.-M.; Kwak, M.-K. Role of the Nrf2-antioxidant system in cytotoxicity mediated by anticancer cisplatin: Implication to cancer cell resistance. Cancer Letters 2008, 260, 96-108. [CrossRef]

72. Wang, X.-J.; Sun, Z.; Villeneuve, N.F.; Zhang, S.; Zhao, F.; Li, Y.; Chen, W.; Yi, X.; Zheng, W.; Wondrak, G.T.; et al. Nrf2 enhances resistance of cancer cells to chemotherapeutic drugs, the dark side of Nrf2. CARCIN 2008, 29, 1235-1243. [CrossRef]

73. Nioi, P.; Nguyen, T. A mutation of Keap1 found in breast cancer impairs its ability to repress Nrf2 activity. Biochem. Biophys. Res. Commun. 2007, 362, 816-821. [CrossRef]

74. Shibata, T.; Kokubu, A.; Gotoh, M.; Ojima, H.; Ohta, T.; Yamamoto, M.; Hirohashi, S. Genetic Alteration of Keap1 Confers Constitutive Nrf2 Activation and Resistance to Chemotherapy in Gallbladder Cancer. Gastroenterology 2008, 135, 1358-1368.e4. [CrossRef]

75. Chen, W.; Sun, Z.; Wang, X.-J.; Jiang, T.; Huang, Z.; Fang, D.; Zhang, D.D. Direct interaction between Nrf2 and p21Cip1/WAF1 upregulates the Nrf2-mediated antioxidant response. Mol. Cell 2009, 34, 663-673. [CrossRef]

76. Lau, A.; Wang, X.-J.; Zhao, F.; Villeneuve, N.F.; Wu, T.; Jiang, T.; Sun, Z.; White, E.; Zhang, D.D. A Noncanonical Mechanism of Nrf2 Activation by Autophagy Deficiency: Direct Interaction between Keap1 and p62. Mol. Cell. Boil. 2010, 30, 3275-3285. [CrossRef]

77. Franco, R.; Schoneveld, O.; Georgakilas, A.G.; Panayiotidis, M.I. Oxidative stress, DNA methylation and carcinogenesis. Cancer Letters 2008, 266, 6-11. [CrossRef]

78. Faraonio, R.; Vergara, P.; Di Marzo, D.; Pierantoni, M.G.; Napolitano, M.; Russo, T.; Cimino, F. p53 Suppresses the Nrf2-dependent Transcription of Antioxidant Response Genes. J. Boil. Chem. 2006, 281, 39776-39784. [CrossRef]

79. Liu, G.H.; Qu, J.; Shen, X. Nf-kappab/p65 antagonizes nrf2-are pathway by depriving cbp from nrf2 and facilitating recruitment of hdac3 to mafk. Biochim. Biophys. Acta 2008, 1783, 713-727. [CrossRef]

80. Levy, S.; Forman, H.J. c-Myc is a Nrf2-interacting protein that negatively regulates phase II genes through their electrophile responsive elements. IUBMB Life 2010, 62, 237-246. [CrossRef]

(C) 2019 by the authors. Licensee MDPI, Basel, Switzerland. This article is an open access article distributed under the terms and conditions of the Creative Commons Attribution (CC BY) license (http://creativecommons.org/licenses/by/4.0/). 